\title{
Cacnalc in the Prefrontal Cortex Regulates Depression-Related Behaviors via REDDI
}

\author{
Zeeba D Kabir ${ }^{1,4}$, Anni S Lee ${ }^{1,2,4}$, Caitlin E Burgdorf ',2, Delaney K Fischer', Aditi M Rajadhyaksha', \\ Ethan Mok', Bryant Rizzo', Richard C Rice', Kamalpreet Singh', Kristie T Ota ${ }^{3}$, Danielle M Gerhard ${ }^{3}$, \\ Kathryn C Schierberl ${ }^{1,2}$, Michael J Glass ${ }^{2}$, Ronald S Duman ${ }^{3}$ and Anjali M Rajadhyaksha ${ }^{*, 1,2}$ \\ 'Division of Pediatric Neurology, Department of Pediatrics, Weill Cornell Medicine, New York, NY, USA; ${ }^{2}$ Feil Family Brain and Mind Research \\ Institute, Weill Cornell Medicine, New York, NY, USA; ${ }^{3}$ Laboratory of Molecular Psychiatry, Department of Psychiatry, Yale University School of \\ Medicine, New Haven, CT, USA
}

\begin{abstract}
The CACNAIC gene that encodes the L-type $\mathrm{Ca}^{2+}$ channel (LTCC) Cavl.2 subunit has emerged as a candidate risk gene for multiple neuropsychiatric disorders including bipolar disorder, major depressive disorder, and schizophrenia, all marked with depression-related symptoms. Although cacnalc heterozygous (HET) mice have been previously reported to exhibit an antidepressant-like phenotype, the molecular and circuit-level dysfunction remains unknown. Here we report that viral vector-mediated deletion of cacnalc in the adult prefrontal cortex (PFC) of mice recapitulates the antidepressant-like effect observed in cacna l c HET mice using the sucrose preference test (SPT), forced swim test (FST), and tail suspension test (TST). Molecular studies identified lower levels of REDDI, a protein previously linked to depression, in the PFC of HET mice, and viral-mediated REDDI overexpression in the PFC of these HET mice reversed the antidepressant-like effect in SPT and TST. Examination of downstream REDDI targets found lower levels of active/phosphorylated Akt (S473) with no change in $\mathrm{mTORCI}$ phosphorylation. Examination of the transcription factor FoxO3a, previously linked to depressionrelated behavior and shown to be regulated in other systems by Akt, revealed higher nuclear levels in the PFC of cacna l c HET mice that was further increased following REDD I-mediated reversal of the antidepressant-like phenotype. Collectively, these findings suggest that REDDI in cacna / c HET mice may influence depression-related behavior via regulation of the FoxO3a pathway. Cacna / $c$ HET mice thus serve as a useful mouse model to further study cacna l c-associated molecular signaling and depression-related behaviors relevant to human CACNA / C genetic variants.

Neuropsychopharmacology (2017) 42, 2032-2042; doi:I 0. I 038/npp.20 I6.27I; published online 4 January 2017
\end{abstract}

\section{INTRODUCTION}

Depression is the most prevalent lifetime psychiatric disorder (Kessler et al, 2005). Despite its rising prevalence, our understanding of the underlying biological mechanisms, particularly those resulting from genetic factors, remains largely unknown.

Genome-wide association studies have linked several intronic single-nucleotide polymorphisms (SNPs) within the CACNA1C gene with multiple neuropsychiatric disorders, including major depressive disorder (MDD), bipolar disorder (BD), and schizophrenia (SCZ), which manifest with depressive symptoms (Heyes et al, 2015). To date, one rodent study has reported that constitutive cacnalc heterozygous (HET) mice with global 50\% knockdown of the

*Correspondence: Dr AM Rajadhyaksha, Division of Pediatric Neurology, Department of Pediatrics, Weill Cornell Medicine, 1300 York Avenue, Box 91, New York, NY 10065, USA, Tel: +212.746.5999, Fax: +2 12.746.400 I, E-mail: amr20 I I@med.cornell.edu

${ }^{4}$ Equally contributed as co-first authors.

Received 12 May 2016; revised I November 2016; accepted 25 November 2016; accepted article preview online 6 December 2016
$\mathrm{Ca}_{\mathrm{v}} 1.2$ protein display an anti-depressive phenotype (Dao et al, 2010), demonstrating that loss of $\mathrm{Ca}_{\mathrm{v}} 1.2$ can regulate depressive-like behaviors in rodent models. However, the molecular pathways by which altered $\mathrm{Ca}_{\mathrm{v}} 1.2$ channel function influence depression-related behavior remains unknown.

Evidence from animal studies supports the significant contribution of altered transcriptional regulation in the pathophysiology of depression (Bagot et al, 2014; Vialou et al, 2013). $\mathrm{Ca}_{\mathrm{v}} 1.2$ channels are critical modulators of several cellular processes that have been implicated in the development of depression (Bhat et al, 2012; Kabir et al, 2016). These include activity-dependent gene expression related to neuronal plasticity, dendritic growth, and the establishment of transcriptional networks (Ebert and Greenberg, 2013; Krey et al, 2013), suggesting that perturbations in $\mathrm{Ca}_{\mathrm{v}} 1.2$ signaling can lead to depressive phenotypes.

Recently, we reported higher levels of the protein REDD1 (regulated in development and DNA damage responses 1; also known as DDIT4 or RTP801) in the prefrontal cortex (PFC) of depressed patients (Ota et al, 2014). Furthermore, in rodents, using the chronic unpredictable stress (CUS)- 
induced model of depression, REDD1 was found to regulate depressive-like behavior via inhibition of the Akt/mTOR (mammalian target of rapamycin) pathway (Ota et al, 2014). Although the transcriptional regulation of REDD1 in the brain is unknown, there is evidence of control of REDD1 expression by CREB (Lee et al, 2015), a transcription factor activated by LTCCs (Rajadhyaksha et al, 1999). Another candidate protein linked to human depression and rodent depressive-like behaviors (Mao et al, 2007; Polter et al, 2009; Wang et al, 2015) along with REDD1 activity (Hulmi et al, 2012) is FoxO3a, family member of the forkhead Box, Class $\mathrm{O}$ transcription factors (FoxO).

Using a combination of behavioral, molecular, and viral vector-mediated gene transfer strategies, we examined the role of cacnalc $\left(\mathrm{Ca}_{\mathrm{v}} 1.2\right)$ in depression-related behaviors. Given evidence that the PFC is implicated in clinical depression (Kang et al, 2012; Rajkowska et al, 1999) and rodent depressive-like behavior (Covington et al, 2010), and data showing that depressed CACNA1C SNP carriers show altered neural processing within the PFC (Backes et al, 2014), we investigated cacnalc pathways in the PFC. We demonstrate that reducing levels of cacnalc $\left(\mathrm{Ca}_{\mathrm{v}} 1.2\right)$ in the PFC of mice has an antidepressant-like effect, and overexpression of REDD1 in the PFC of cacnalc HET mice reverses this effect by regulating levels of Akt and modulating the phosphorylation and subcellular distribution of FoxO3a.

\section{MATERIALS AND METHODS}

\section{Animals}

Constitutive cacnalc $\left(\mathrm{Ca}_{\mathrm{v}} 1.2\right)$ heterozygous (HET) mice, their wild-type (WT) littermates and cacnalc floxed homozygous (cacnal $c^{\mathrm{fl} / \mathrm{fl}}$ ) mice (Moosmang et al, 2005), all on the C57BL/6 J background, were used for all the experiments. HET and control WT mice were generated by crossing male $\mathrm{Ca}_{\mathrm{v}} 1.2^{+/-}$HET mice with female store-bought C57BL/6 J mice (Jackson Laboratories). HET mice were indistinguishable from respective WT littermates in weight, development, and general health. The animals were maintained on a $12-\mathrm{h}$ light/dark cycle (from 6 AM to $6 \mathrm{PM}$ ) and provided food and water ad libitum. All the procedures were conducted in accordance with the Weill Cornell Medicine Institutional Animal Care and Use Committee rules.

\section{Surgeries}

Region-specific deletion of cacnalc was achieved by stereotaxic surgery as previously described (Lee et al, 2012). Adeno-associated viral vector (AAV2/2; Vector BioLabs) expressing either GFP (AAV-GFP) or Cre recombinase (AAV-Cre-GFP) was delivered into the PFC of cacnalct/fl/ mice with a $2.5 \mu \mathrm{l}, 30$-gauge Hamilton syringe at a rate of $0.1 \mu \mathrm{l} / \mathrm{min}$. A volume of $0.75 \mu \mathrm{l} / \mathrm{hemisphere}$ was injected using the coordinates: $+2.3 \mathrm{AP},-2.8 \mathrm{DV}, \pm 1.7 \mathrm{ML}$ at a $30^{\circ}$ angle. To overexpress REDD1 in the PFC of cacnalc HET mice, $1.2 \mu \mathrm{l} / \mathrm{hemisphere}$ of AAV2-REDD1-IRES-eYFP (AAV-REDD1), generated as described previously (Ota et al, 2014), was injected using the coordinates mentioned above. Adeno-associated viral vector lacking REDD1 (AAVeYFP) was used as a control. The mice were allowed to recover for 3 weeks before behavioral testing. For confirmation of injection placement, GFP immunohistochemistry was performed as previously described (Lee $e t$ al, 2012). The mice used for molecular studies were decapitated, brains dissected and sectioned on a $1 \mathrm{~mm}$ brain block. GFP staining was visualized using GFP goggles (BLS-Ltd.com) for placement. The animals with improper bilateral injection placement were excluded from behavioral data analysis.

\section{Basal Locomotion}

Horizontal locomotor activity was assessed by computerassisted activity monitoring software (Med Associates Inc.) for $30 \mathrm{~min}$ as previously described (Lee et al, 2012).

\section{Sucrose Preference Test (SPT)}

In SPT, mice were given a choice between two bottles containing either drinking water or $5 \%$ sucrose. Preliminary studies with $1 \%$ sucrose yielded variable results in the mouse lines used here, and 5\% sucrose has been shown to produce robust sucrose preference in C57BL/6 J mice (Pothion et al, 2004). Twenty-four hours before the start of the behavior (day 0 ), the mice were single housed and remained individually housed for the duration of the behavior. The mice were then habituated to the presence of two drinking bottles (containing 5\% sucrose or water) in their home cage for the next $24 \mathrm{~h}$ (day 1, habituation). Sucrose solution was prepared in drinking water and provided at room temperature. Following this, the mice were given access to both bottles of drinking water and sucrose for a total of $24 \mathrm{~h}$ (day 2 , test). The data reported reflect the amount consumed during this $24 \mathrm{~h}$ test period. To prevent possible effects of side preference in drinking behavior, the positions of the two bottles were switched after habituation and randomized across groups. The body weight of each mouse and mass of water and sucrose consumed were measured for three consecutive days with all measurements recorded at $1500 \mathrm{~h}$. Every mouse tested in SPT underwent the 3-day behavioral paradigm only once. Sucrose preference was calculated as sucrose consumed $(\mathrm{g}) /($ sucrose consumed $(\mathrm{g})+$ water consumed $(\mathrm{g})) \times 100$. Sucrose consumption was calculated as sucrose consumed (g)/water consumed (g), and liquid intake was calculated as liquid (sucrose, water, or total liquid) consumed (g)/body weight (g).

\section{Forced Swim Test (FST)}

FST was performed in a 2 liter beaker containing $1800 \mathrm{ml}$ of $26^{\circ} \mathrm{C}$ water, for $10 \mathrm{~min}$. Each mouse was video recorded using a camera directed to the front of the beaker, and time spent immobile was scored during the entire $10 \mathrm{~min}$ period. 'Immobility' was defined as when a mouse ceased all movements other than those necessary for staying afloat, such as minor tail flicks and one hind-paw flicks. Videos were scored by an experimenter blinded to the conditions using the computer-assisted software ButtonBox v5.1 (Behavioral Research Solutions). Each experiment was scored by the same experimenter for consistency. 


\section{Tail Suspension Test (TST)}

TST was performed for $6 \mathrm{~min}$ by suspending a mouse $30 \mathrm{~cm}$ from the floor using a $17 \mathrm{~cm}$-long adhesive tape $\left(0.75^{\prime \prime}\right.$ wide, Fisherbrand) that was secured to the tail $2 \mathrm{~cm}$ from the tip. A clear hollow climbstopper cylinder $(4 \mathrm{~cm}$ length, $1.5 \mathrm{~cm}$ diameter, $1.3 \mathrm{~g}$ ) was placed around the tail to prevent tail-climbing behavior. Each mouse was video recorded and time spent immobile was scored by an experimenter blinded to the genotypes or treatments using the computerassisted software ButtonBox v5.1. 'Immobility' was described as lack of body movement except for minor front leg movements and oscillating swings owing to the momentum of previous mobility. Each experiment was scored by the same experimenter for consistency.

\section{Subfractionation and Immunoblotting}

For all the molecular experiments, mice were killed by rapid decapitation, brains were isolated, and bilateral PFC was dissected using a 17-gauge stainless-steel stylet. Total protein lysates were isolated as previously described (Tropea et al, 2011). Nuclear (P1), cytoplasmic (S1), and synaptosomal (P2) fractions were generated as previously published (Knackstedt et al, 2010). Tissue was homogenized in $0.01 \mathrm{M}$ sucrose/0.4 mM HEPES buffer containing protease and phosphatase inhibitors and centrifuged at $1000 \times \mathrm{g}$. The supernatant was processed for S1 and P2 fractions and the pellet (P1) was processed for nuclear fraction. For S1 and P2 fractions, the supernatant was spun at $1000 \times \mathrm{g}$. The obtained supernatant was spun again at $12000 \times \mathrm{g}$ to obtain the S1 (supernatant) and P2 (pellet resuspended in $4 \mathrm{mM}$ HEPES/ $1 \mathrm{mM}$ EDTA buffer) fractions. For the nuclear fraction, P1 was resuspended in sucrose buffer $(10 \mathrm{mM}$ Tris- $\mathrm{HCl}, 0.32 \mathrm{M}$ sucrose, $1 \mathrm{mM}$ EDTA, $1 \mathrm{mM}$ EGTA, $5 \mathrm{mM}$ DTT), incubated on ice for $10 \mathrm{~min}$ and spun at $1500 \times \mathrm{g}$. The resulting pellet was resuspended in sucrose buffer $(50 \mathrm{mM}$ Tris- $\mathrm{HCl}, 0.32 \mathrm{M}$ sucrose, $10 \%$ glycerol, $400 \mathrm{mM} \mathrm{NaCl}, 1 \% \mathrm{NP}-40$ ), incubated on ice for $30 \mathrm{~min}$ and spun at $25000 \times \mathrm{g}$. The supernatant was collected as the nuclear fraction.

The protein concentration was determined using the BCA assay (Thermo Fisher Scientific). Twenty micrograms of protein lysate was separated on a $10 \%$ SDS protein gel with a Kaleidoscope-prestained protein standard (Bio-Rad). The blots were blocked in 5\% non-fat dry milk and incubated in primary antibody (Table S1) for $12-48 \mathrm{~h}$ at $4{ }^{\circ} \mathrm{C}$. The blots were incubated in horseradish peroxidase-linked IgG conjugated secondary antibody for $1 \mathrm{~h}$. The protein bands were visualized by chemiluminescence solution (Western Lightening, Perkin Elmer Life Sciences) and quantified at the molecular weights indicated in Supplementary Table 1. GAPDH was used as a loading control.

\section{BDNF ELISA Assay}

Tissue was homogenized in lysis buffer (150 mM NaCl, $1 \%$ Triton X-100, $25 \mathrm{mM}$ HEPES, $2 \mathrm{mM} \mathrm{NaF}$ ) and incubated on a rotisserie shaker at $4{ }^{\circ} \mathrm{C}$ for $1 \mathrm{~h}$. Homogenized tissue was centrifuged at $20000 \times \mathrm{g}$ and the supernatant containing total protein was quantified using BCA protein assay. Mature BDNF protein was measured using the BDNF Emax
ImmunoAssay (ELISA) system (Promega) as previously published (Kabir et al, 2012).

\section{Quantitative Real-Time PCR (QPCR)}

RNA was isolated and QPCR was performed as previously described (Schierberl et al, 2011). Redd1, gapdh, and foxo3a mRNA levels were measured using mRNA-specific primers (Supplementary Table 2). Cycle threshold (Ct) values for target genes were normalized to the housekeeping gene gapdh (QuantiTect Primer assay QT01658692; Qiagen). Each experiment was performed in triplicate, and the values were averaged.

\section{Statistics}

For all the experiments, the data were first analyzed for normality using the D'Agostino-Pearson test. For data normally distributed, a parametric independent-samples Student's $t$-test was used, and if the variances were significantly different, a Welch's correction was performed. For data that was not normally distributed, a nonparametric independent-samples Mann-Whitney $U$-test was used. For all REDD1 overexpressing behavioral data, a two-way ANOVA was performed followed by Bonferroni post hoc analysis for all variables displaying main effects. A value of $p \leqslant 0.05$ was considered to be statistically significant, and all analyses were performed using GraphPad Prism 5.0 (GraphPad Software).

\section{RESULTS}

\section{Focal Knockdown of Cacnalc in the PFC has an Antidepressant-Like Effect}

As homozygous deletion of cacnalc results in embryonic lethality (Seisenberger et al, 2000), we utilized cacna1c HET mice and WT littermate controls. To confirm previous findings that heterozygous cacnalc-deficient mice exhibit antidepressant-like behavior (Dao et al, 2010), HET and WT mice were tested in SPT (Pothion et al, 2004), FST (Porsolt et al, 2001), and TST (Can et al, 2012), common behavioral tests that measure depression-related behavior. In SPT, HET mice displayed increased sucrose preference (Figure $1 \mathrm{a} ; t(11)=2.65 ; p=0.0226$ ) and sucrose consumption (Figure 1b; Mann-Whitney $U=26$; $p=0.0086$ ), and demonstrated higher, though not significant, sucrose intake (Supplementary Figure 1a), and lower water intake (Supplementary Figure 1a; Mann-Whitney $U=35$; $p=0.0343$ ). No difference in total liquid intake was observed between HET and WT mice (Supplementary Figure 1c). In both FST (Figure 1c) and TST (Figure 1d), HET mice exhibited significantly lower immobility time compared with WT mice (FST: $t(21)=2.143 ; p=0.044$; TST: $t(15)=3.802$; $p=0.0017)$. No difference in basal locomotion was observed between the groups (Figure 1e). These results confirmed previous findings (Dao et al, 2010) that loss of cacna1c results in an antidepressant-like effect as demonstrated by higher sucrose preference and lower immobility.

To more precisely investigate the brain substrate modulating the antidepressant-like effect, we generated focal knockdown of cacna1c in the PFC by bilateral delivery of AAV2/2- 


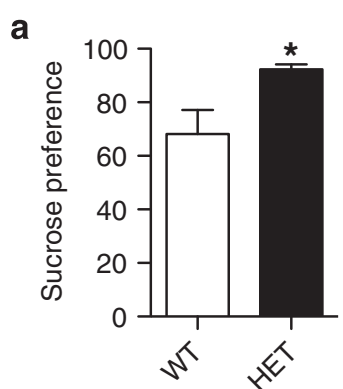

b
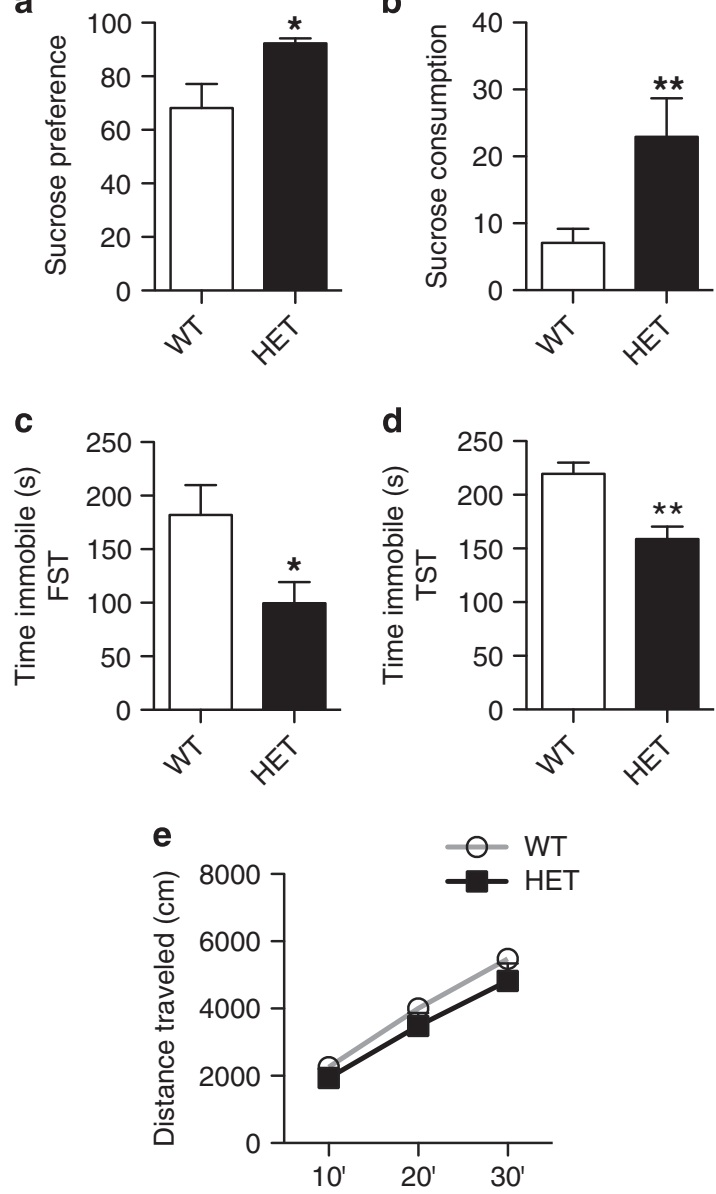

Figure I Cacnalc heterozygous mice display antidepressant-like behavior. (a, b) Cacna l c HET mice show significantly higher sucrose preference (a) and sucrose consumption (b) compared with WT mice in the sucrose preference test (WT $n=12, H E T n=12$ ). (c, d) HET mice spend significantly less time immobile than WT mice in the forced swim test (c) and the tail suspension test (d) (FST: WT $n=14$, HET $n=9$; TST: WT $n=8$, HET $n=9$ ). (e) HET mice travel similar distance as WT mice in the basal locomotor activity test (WT $n=12$, HET $n=10)$. * $p<0.05$, *** $p<0.0$ I vs WT. Error bars are mean \pm SEM.

Cre in adult cacnal $c^{\mathrm{fl} / \mathrm{fl}}$ mice (Figures $2 \mathrm{a}$ and $\mathrm{b}$ ). This resulted in significantly lower levels of cacnalc mRNA compared with control AAV2/2-GFP injected mice (mRNA fold change compared with controls: AAV2/2-GFP $(n=6), 1 \pm 0.04$ vs AAV2/2-Cre $(n=6), 0.46 \pm 0.10 ; t(10)=4.824, p<0.001)$. Knockdown of cacnalc in the PFC (AAV-Cre) had no effect on basal locomotion (Figure 2c). However, AAV-Cre mice displayed increased sucrose consumption (Figure 2d; $t(15)=2.483 ; p=0.0253)$ and, though not significant, had increased sucrose intake (Supplementary Figure 1d) and decreased water intake (Supplementary Figure 1e; $t(15)=2.292 ; p=0.0368$ ). No difference in total liquid intake was observed between the groups (Supplementary Figure 1f). Similarly, in FST, AAV-Cre mice exhibited decreased time spent immobile compared with control mice (Figure 2e; $t(10)=2.853 ; p=0.0172)$. These results demonstrated that focal knockdown of cacnalc in the PFC induces a similar antidepressant-like effect as observed in cacnalc HET mice.
Lower Levels of REDD1 mRNA and Protein in the PFC of Cacna1c Heterozygous Mice

$\mathrm{Ca}_{\mathrm{v}} 1.2$ has a key role in regulating activity-dependent gene expression essential for neuronal structure and function (Ebert and Greenberg, 2013). We have recently shown that REDD1 is elevated in the PFC of depressed patients and regulates depression-related behavior in a rodent model of depression (Ota et al, 2014). Thus, to begin to investigate the molecular mechanisms underlying the antidepressant-like phenotype observed in HET mice (Figure 1), we examined REDD1 mRNA and protein levels in the PFC. We found significantly lower levels of both REDD1 mRNA (Figure 3a; $t(18)=2.468 ; \quad p=0.0238$ ) and protein (Figure 3b; $t(11)=5.913 ; p=0.0001)$ in HET mice compared with WT mice, demonstrating that loss of cacnalc downregulates REDD1 expression in the PFC.

\section{Lower Levels of Akt But Not mTOR Phosphorylation in the PFC of Cacna1c Heterozygous Mice}

In multiple systems, including the brain, REDD1 has been shown to stabilize the TSC1-TSC2 complex and regulate the Akt/mTORC1 pathway (Maiese et al, 2013; Ota et al, 2014; Figure 3c). Examination of total protein levels (Figure 3d) of TSC2, mTOR, and its downstream target p70S6Kinase1 (p70S6K1), and Akt revealed no differences between HET and WT mice indicating that reduced cacnalc did not alter protein expression of these molecules. Next, we examined changes in phosphorylation levels of the target proteins, as a marker of altered activity. No difference in phospho(P)TSC2 T1462, P-mTOR S2448 (mTORC1) or P-p70S6K1 T389 was observed between HET and WT mice (Figure 3d). However, lower levels of P-Akt S473 $(t(11)=2.282$; $p=0.0164$ ) but not P-Akt T308 were observed (Figure 3d). P-Akt S473 is also regulated by mTORC2, a protein activated by mTOR phosphorylation at S2481 (Huang et al, 2013; Figure 3c). No difference in P-mTOR S2481 was observed between HET and WT mice (Figure 3d). Taken together, the above findings established that reduced $\mathrm{Ca}_{\mathrm{v}} 1.2$ in the $\mathrm{PFC}$ of cacnalc HET mice downregulates the Akt pathway via phosphorylation of S473 but not mTOR signaling.

\section{Dysregulated FoxO3a in the PFC of Cacna1c Heterozygous Mice}

As we observed no change in the mTOR pathway, a downstream target of REDD1 (Ota et al, 2014), we next examined the FoxO family of transcription factors that have been previously linked to Akt (Wang et al, 2014) and REDD1 in other systems (Hulmi et al, 2012) and shown to regulate depression-related behaviors (Mao et al, 2007; Polter et al, 2009). FoxO1 and FoxO3a have been characterized in the adult rodent brain with FoxO3a being the predominant isoform expressed in the adult cortex (Hoekman et al, 2006). In the mouse PFC, we detected no FoxO1 protein (data not shown) and therefore focused on FoxO3a. No difference in FoxO3a mRNA (Supplementary Figure 2a) and total protein (Supplementary Figure 2b) levels was observed in the PFC of HET and WT mice. However, nuclear FoxO3a levels were significantly higher in the PFC of HET mice compared with WT mice $(t(10)=4.892 ; p=0.0006)$ with no change in the 
cytoplasmic FoxO3a levels (Figure 3e). As phosphorylation in part, has been shown to be regulated by antidepressants (Polter et al, 2009) and in other systems to regulate FoxO3a's transcriptional activity (Tzivion et al, 2011), we next examined levels of FoxO3a phosphorylation (at S253 and T32). We found significantly higher levels of P-FoxO3a S253 but not T32 in the nucleus of HET mice compared with WT mice (Figure 3f; $t(10)=2.536 ; p=0.0296$ ), paralleling higher total nuclear FoxO3a levels (Figure 3e).

FoxO3a activity is additionally regulated by the neurotrophic factor, BDNF (Zhu et al, 2004), a protein linked to the pathogenesis of depression (Martinowich et al, 2007). As LTCCs are key regulators of activity-dependent BDNF expression (Tao et al, 1998), we measured BDNF protein levels and found no difference in the PFC of HET mice compared with WT mice (Figure $3 g$ ).

\section{Overexpression of REDD1 in the PFC Reverses the Antidepressant-Like Effect in Cacnalc Heterozygous Mice}

To directly test whether REDD1 in the PFC has a causal role for the antidepressant-like effect observed in cacnalc HET mice (Figure 1), we utilized a REDD1-expressing viral vector (AAV-REDD1; Ota et al, 2014; Figure 4a). AAV-REDD1 or control AAV-eYFP was injected bilaterally into the PFC of HET and WT mice (Figure 4b). AAV-REDD1 had no effect on basal locomotion in HET or WT mice (Figure 4e). In SPT, overexpression of REDD1 in HET mice reversed the higher sucrose preference (Figure $4 \mathrm{~d}$ ) and sucrose intake (Supplementary Figure 3a) seen in control HET mice to that of control WT mice. AAV-eYFP HET mice exhibited significantly higher sucrose preference compared with
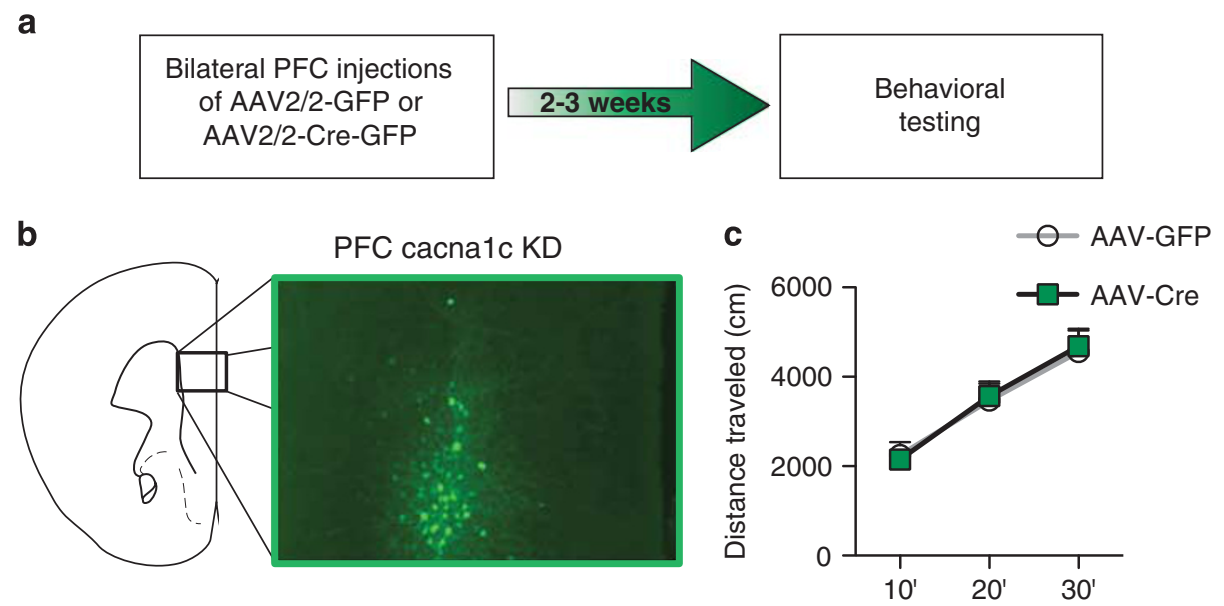

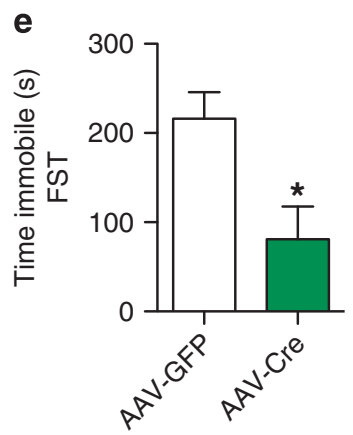

Figure 2 Knockdown of cacnalc in the PFC has an antidepressant-like effect in mice. (a) Experimental outline used. (b) Representative image of green fluorescent protein (GFP)-positive cells expressed by AAV-Cre stereotaxically injected into the PFC of cacnal $\mathrm{c}^{\text {fl/fl }}$ mice. (c) AAV-Cre and AAV-GFP mice travel similar distances in the basal locomotor activity test ( $A A V-G F P n=8, A A V-C r e n=8$ ). (d) AAV-Cre mice show significantly higher sucrose consumption than control AAV-GFP mice in the sucrose preference test (AAV-GFP $n=9, A A V-C r e n=8$ ). (e) AAV-Cre mice spend significantly less time immobile in the forced swim test compared with control AAV-GFP mice (AAV-GFP $n=6$, AAV-Cre $n=6$ ). ${ }^{*} p<0.05$ vs AAV-GFP. Error bars are mean \pm SEM.

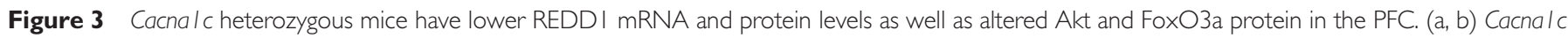

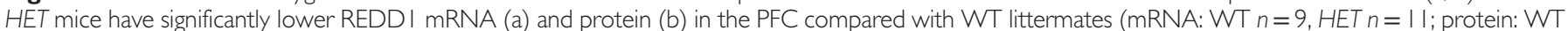

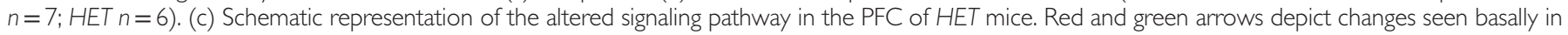

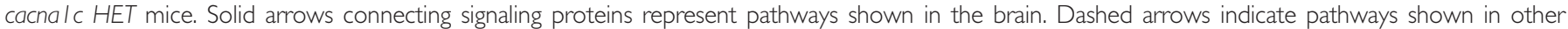

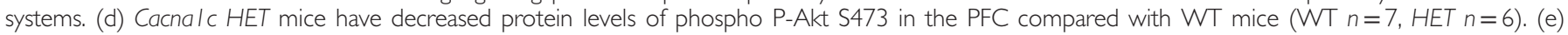

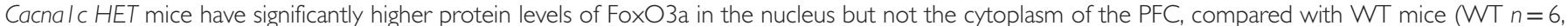

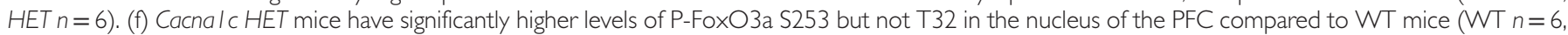

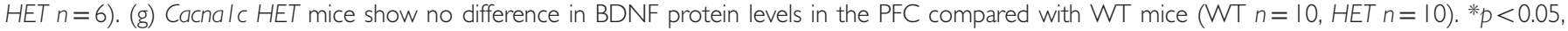
***** $<0.001$ vs WT. Error bars are mean \pm SEM.
} 
AAV-eYFP WT mice, as expected, and AAV-REDD1 in HET mice lowered the preference (Figure 4d; Two-way ANOVA, genotype $\times$ treatment, $F_{1,40}=13.03, p=0.0008$; Bonferroni $p<0.05)$. Similarly, AAV-eYFP HET mice exhibited significantly higher sucrose intake compared to AAV-eYFP WT mice, with AAV-REDD1 significantly reducing sucrose intake (Supplementary Figure 3a; Two-way ANOVA, genotype $\times$ treatment, $F_{1,40}=11.58, p=0.0015 ;$ Bonferroni $p<0.01)$. Even though not significant, AAV-eYFP HET mice had lower water intake than AAV-eYFP WT mice that increased with AAV-REDD1 injection (Supplementary Figure 3b; Two-way ANOVA, genotype $\times$ treatment, a

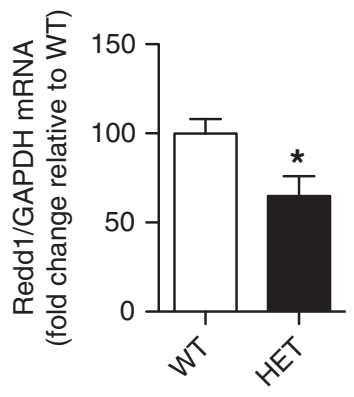

b

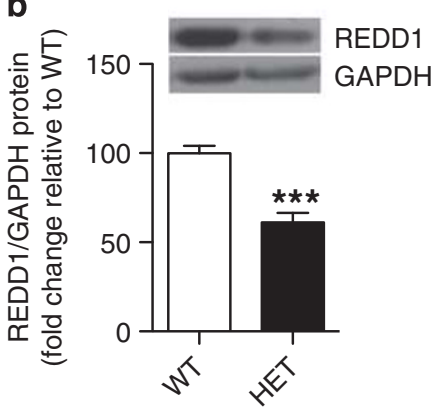

C

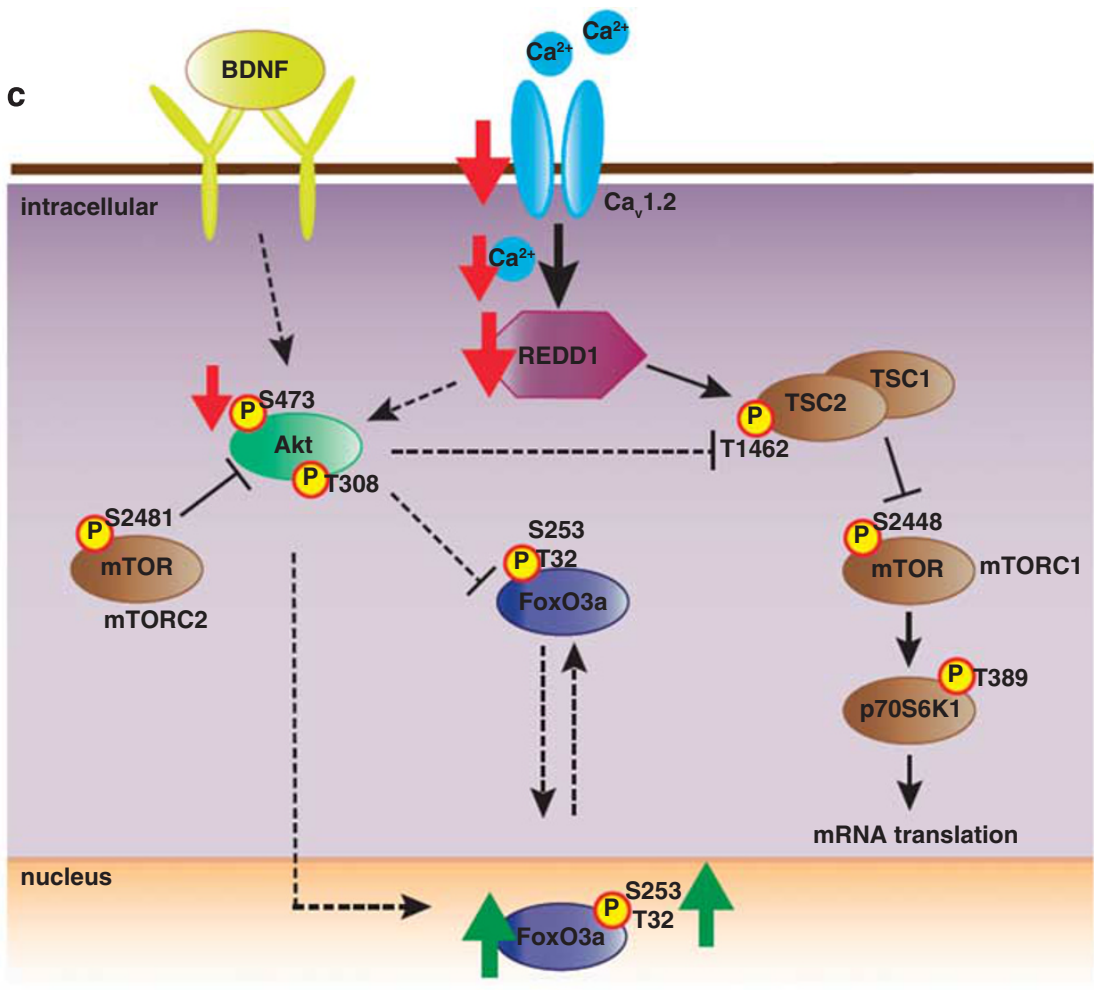

d

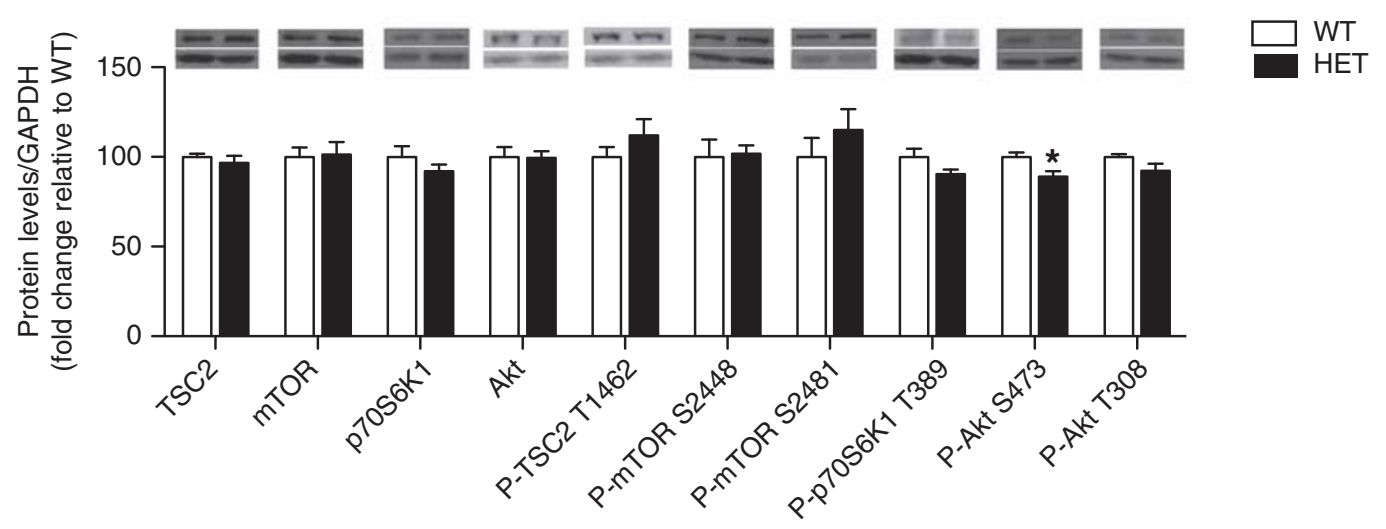

e

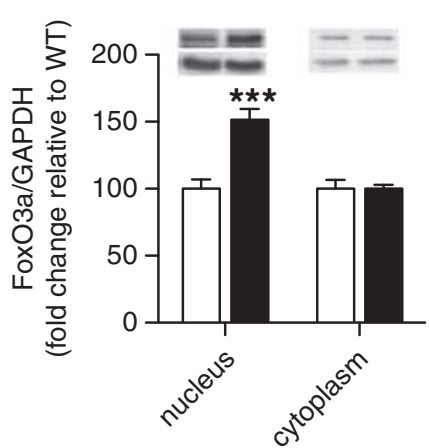

f

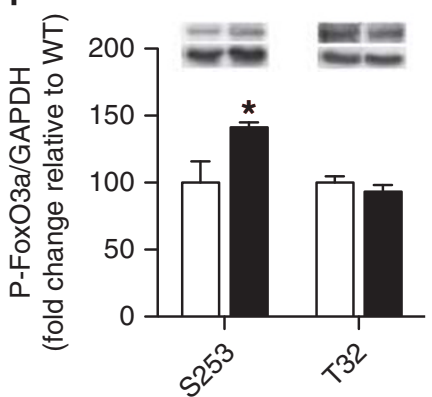

g

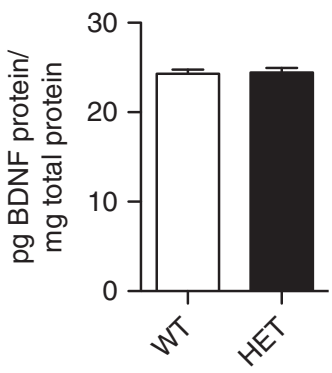



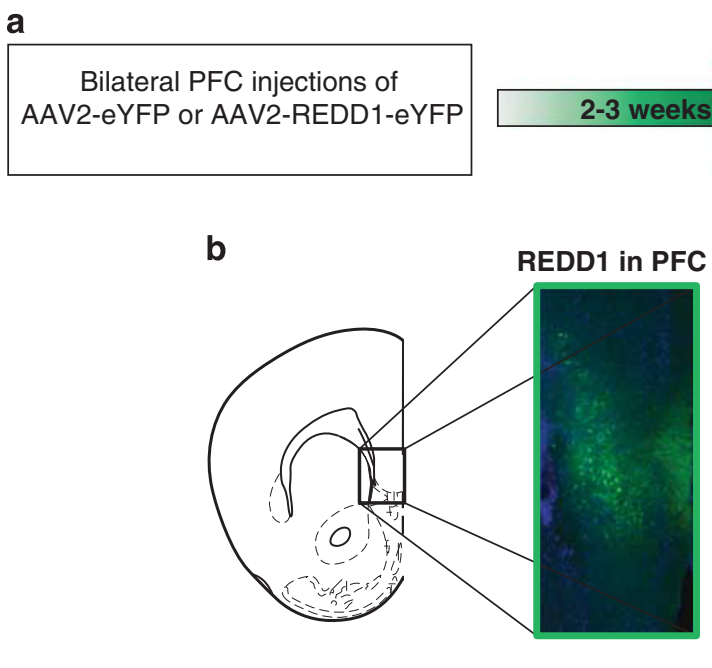
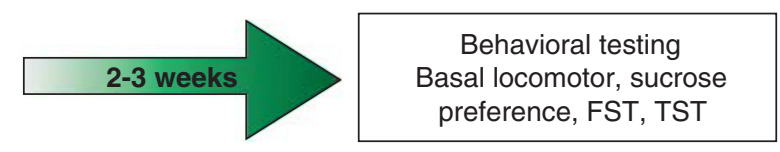

Sacrificed for westerns
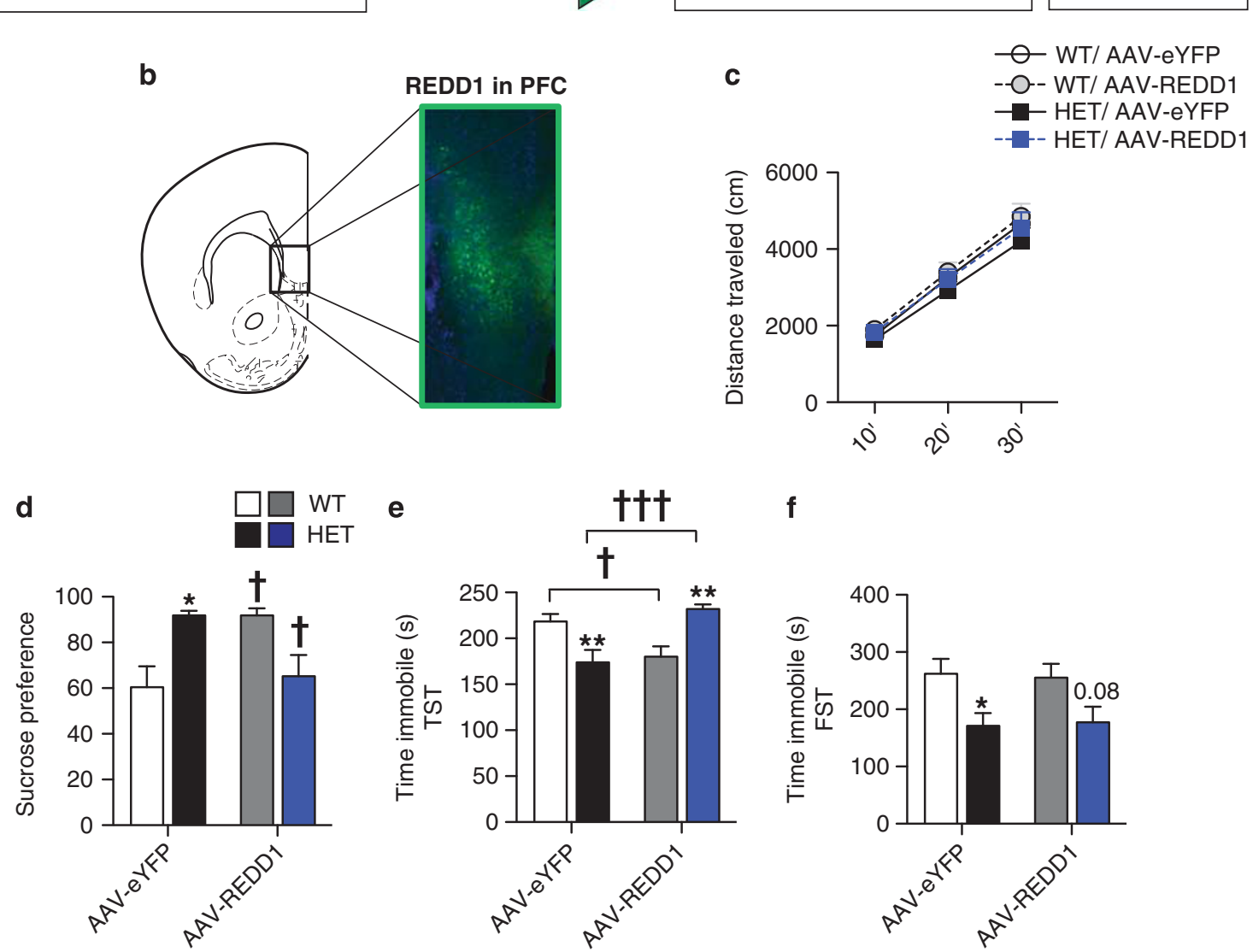

Figure 4 REDDI over-expression in PFC of cacnalc heterozygous mice reverses the antidepressant-like effect. (a) Experimental outline used. (b) Representative image of green e-YFP-positive cells expressed by AAV-REDD I-eYFP stereotaxically delivered into the PFC of cacna I c HET mice. (c) AAVREDDI in the PFC does not alter total distance traveled in the basal locomotor activity test (WT: AAV-eYFP $n=\mid I, A A V-R E D D I n=9 ; H E T$ : AAV-eYFP $n=7$, AAV-REDDI $n=8$ ). (d) AAV-eYFP HET mice display significantly higher sucrose preference compared with AAV-eYFP WT mice. Sucrose preference of HET mice is significantly lowered by AAV-REDDI. In WT mice, AAV-REDDI significantly increased sucrose preference compared with control AAV-eYFP mice (WT: AAV-eYFP $n=14$, AAV-REDDI $n=8$; HET: AAV-eYFP $n=10$, AAV-REDDI $n=12$ ). (e) AAV-eYFP HET mice display significantly lower immobility time in the tail suspension test compared with control AAV-eYFP WT mice. Immobility time of HET mice is significantly increased by AAV-REDD I overexpression. In WT mice, AAV-REDDI significantly decreased immobility time compared with control AAV-eYFP mice (WT: AAV-eYFP $n=I I$, AAVREDDI $n=9$; HET: AAV-eYFP $n=7$, AAV-REDDI $n=8$ ). (f) AAV-eYFP HET mice display significantly lower immobility time in the forced swim test compared with control AAV-eYFP WT mice that remained unchanged by AAV-REDDI (WT: AAV-eYFP $n=\mid 0, A A V-R E D D I n=9 ;$ HET: AAV-eYFP $n=10$, AAV-REDDI $n=13) .{ }^{*} p<0.05,{ }^{*} * p<0.0 \mid$ vs WT for the respective viral treatment; ${ }^{\dagger} p<0.05,{ }^{t+t} p<0.00 \mid$ vs AAV-eYFP of the respective genotype. Error bars are mean \pm SEM.

$\left.\mathrm{F}_{1,40}=4.409, p=0.0421\right)$. AAV-REDD1 in HET mice also reduced overall liquid intake compared with AAV-eYFP HET mice (Supplementary Figure 3c; Two-way ANOVA, Main effect of treatment, $\mathrm{F}_{1,40}=4.762, p=0.035$; Bonferroni $p<0.05)$. Surprisingly, in WT mice, AAV-REDD1 significantly increased sucrose preference (Figure 4d; Bonferroni $p<0.05)$ and although not significant, increased sucrose intake (Supplementary Figure 3a) and decreased water intake (Supplementary Figure $3 \mathrm{~b}$ ), with no effect on total liquid intake (Supplementary Figure 3c).

In TST, similar to our findings in Figure 1, AAV-eYFP HET mice spent significantly less time immobile compared with AAV-eYFP WT mice and REDD1 overexpression reversed this effect, with AAV-REDD1 HET mice exhibiting increased immobility time compared with AAV-eYFP HET mice (Figure 4e; Two-way ANOVA, genotype $\times$ treatment, $\mathrm{F}_{1,31}=24.33, p<0.0001$; Bonferroni $\left.p<0.001\right)$. However, similar to the phenotype observed in SPT, AAV-REDD1 in WT mice decreased immobility time to the level of the AAVeYFP HET mice (Figure 4e; Bonferroni $p<0.05$ ). Interestingly, in contrast to the effect of AAV-REDD1 in TST, REDD1 overexpression in HET or WT mice had no effect in FST. Similar to our previous findings (Figure 1c), AAV-eYFP HET mice spent significantly less time immobile in FST that remained unchanged with REDD1 overexpression (Figure 4f; Two-way ANOVA, main effect of genotype, $\mathrm{F}_{1,38}=10.31, p=0.0027$; Bonferroni $p<0.05$ ). Together, these results demonstrated that cacnalc and REDD1 are causally linked to the antidepressant-like effect as measured in SPT and TST. 

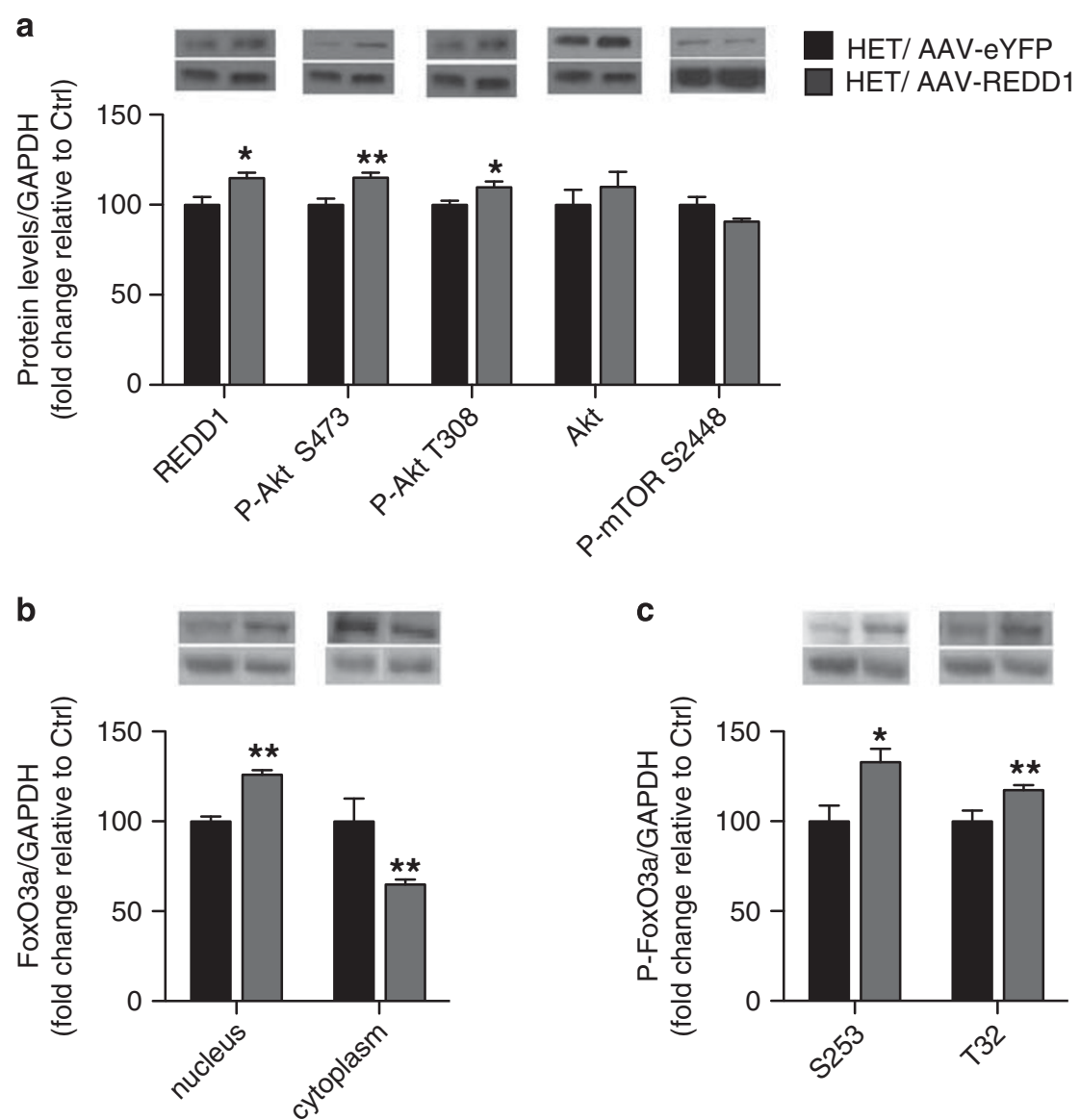

Figure 5 REDDI over-expression in PFC of cacna l c heterozygous mice increases levels of phosphorylated Akt and nuclear FoxO3a in the PFC. (a) AAVREDDI in the PFC of cacna I c HET mice significantly increases protein levels of REDDI and P-Akt at S473 and T308 compared with control AAV-eYFP HET mice. (b) AAV-REDDI in the PFC of cacna I c HET mice significantly increased FoxO3a protein in the nucleus and decreased levels in the cytoplasm compared with control AAV-eYFP HET mice. (c) AAV-REDDI in the PFC of cacna l c HET mice significantly increased levels of P-FoxO3a protein at S253 and T32 in the nucleus compared with control AAV-eYFP HET mice (HET/AAV-eYFP $n=4$, HET/AAV-REDDI $n=5-7$ ). * $p<0.05$, *** $p<0.0$ I vs HET/AAV-eYFP. Error bars are mean \pm SEM.

Next, we examined the effect of REDD1 overexpression on levels of phosphorylated Akt and FoxO3a in the PFC of HET mice. As expected, AAV-REDD1 in the PFC of HET mice increased REDD1 protein compared with AAV-eYFP HET mice (Figure $5 \mathrm{a} ; t(9)=2.314 ; p=0.045$ ). AAV-REDD1 in HET mice significantly increased P-Akt S473 (Figure 5a; $t(9)=3.252 ; p=0.01)$, and further increased P-Akt T308 (Figure 5a; $t(9)=3.012, p=0.0147$ ) that was basally unaltered (Figure 3d). AAV-REDD1 had no effect on total Akt and P-mTOR S2448 levels (Figure 5a). Next, we examined the effect of REDD1 overexpression on nuclear levels of total and phosphorylated FoxO3a. Compared with control mice, AAV-REDD1 in HET mice further increased nuclear levels of total FoxO3a (Figure 5b; $t(11)=6.209 ; p<0.001$ ) over that already observed basally (Figure 3e), while significantly decreasing levels of FoxO3a in the cytoplasm (Figure 5b; $t(10)=4.08, p=0.0022)$. Higher nuclear FoxO3a paralleled higher nuclear P-FoxO3a S253 (Figure $5 c ; t(11)=2.544$; $p=0.0273)$ in AAV-REDD1 HET mice compared with AAVeYFP HET mice. In addition, AAV-REDD1 also elevated nuclear P-FoxO3a T32 (Figure $5 c ; t(12)=2.977, p=0.0116$ ) that was unaltered basally in HET mice (Figure 3f).

\section{DISCUSSION}

This study describes a previously unidentified link between cacnalc $\left(\mathrm{Ca}_{\mathrm{v}} 1.2\right)$ and REDD1 in regulating depressionrelated behavior. We demonstrate that knockdown of cacnalc in the adult PFC has an antidepressant-like effect. This recapitulates and further extends the phenotype observed in cacnalc HET mice previously reported by Dao et al (2010) and supports previous studies that have demonstrated antidepressant-like effects of LTCC pharmacological blockers (Cohen et al, 1997; Mogilnicka et al, 1987, 1988). At the molecular level, we find lower levels of REDD1 mRNA and protein in the PFC of cacnalc HET mice and demonstrate that overexpression of REDD1 is sufficient to reverse the antidepressant-like effect as measured in SPT and TST. Examination of downstream molecular targets reveals altered regulation of Akt and $\mathrm{FoxO} 3 \mathrm{a}$ as a consequence of loss of cacna1c and REDD1. Taken together, the findings that loss of cacna1c in the PFC alters levels of molecules (REDD1, Akt, and FoxO3a) that have previously been linked to either human depression, rodent depressive-like behavior, or to the effects of antidepressants (Ota et al, 2014; Wang et al, 2015), provides a novel anatomical and molecular framework to 
study the role of cacna1c in modulating depression-related behavior.

The impact of noncoding CACNA1C SNPs on transcript levels, $\mathrm{Ca}_{\mathrm{v}} 1.2$ function, and the subsequent contribution to disease symptoms is a key question in the field. Our finding that reduced $\mathrm{Ca}_{\mathrm{v}} 1.2$ induces an antidepressant-like effect suggests that gain of $\mathrm{Ca}_{\mathrm{v}} 1.2$ function could possibly contribute to depressive symptoms. This is supported by gain of $\mathrm{Ca}_{\mathrm{v}} 1.2$ channel function observed in induced pluripotent stem cell (iPSC)-derived neurons generated from $\mathrm{BD}$ patients harboring the rs1006737 CACNA1C risk SNP (Yoshimizu et al, 2015). The only currently existing mouse model with a gain of $\mathrm{Ca}_{\mathrm{v}} 1.2$ function is the Timothy syndrome (TS) mouse model of autism (Bader et al, 2011) in which depression-related behavioral tests have not been performed to date. Our hypothesis of the involvement of $\mathrm{Ca}_{\mathrm{v}} 1.2$ in depression-related behavior is supported by the report of depression in a TS patient (Splawski et al, 2005) and a patient with TS developing BD in adulthood (Gershon et al, 2014). However, given the finding by Roussos et al (2014) that a SCZ-associated SNP results in decreased cacnalc mRNA, the impact of CACNA1C SNPs on depressive symptoms may be more complex and governed by genetic and cell-type environments (Koester and Insel, 2016), a topic that requires further investigation.

One key mechanism believed to underlie depressive symptoms is structural alterations of the PFC, such as neuronal atrophy and loss of synaptic connections, as observed in the PFC of human subjects with depression (Rajkowska et al, 1999). Consistent with this, brain imaging studies have revealed altered brain structure and connectivity in human CACNA1C SNP carriers with MDD, SCZ, or BD (Kabir et al, 2016). The effect of loss of $\mathrm{Ca}_{\mathrm{v}} 1.2$ on PFC structure remains unknown, however, dendritic retraction has been reported in the $\mathrm{TS} \mathrm{Ca}_{\mathrm{v}} 1.2$ gain-of-function mouse model (Krey et al, 2013), suggesting that dysregulated $\mathrm{Ca}_{\mathrm{v}} 1.2$ signaling may contribute to PFC structural changes. Our data suggest that one mechanism that could drive such changes involves $\mathrm{Ca}_{\mathrm{v}} 1.2$-mediated transcriptional regulation of REDD1. Increase in REDD1 expression within the PFC of rodents is necessary and sufficient to cause loss of synapse number (Ota et al, 2014). Thus, it is plausible that REDD1 may mediate the effects of altered $\mathrm{Ca}_{\mathrm{v}} 1.2$ function on PFC structure. Future structural studies in the PFC of cacnalc HET mice (with and without REDD1 overexpression) are needed to definitively link synaptic changes to depressivelike behavior. The precise mechanism by which $\mathrm{Ca}_{\mathrm{v}} 1.2$ regulates REDD1 expression remains unknown. One potential route is via the transcription factor CREB, a downstream target of $\mathrm{Ca}_{\mathrm{v}} 1.2$ (Rajadhyaksha et al, 1999; Zhang et al, 2006) and regulator of REDD1 gene expression as shown in other systems (Lee et al, 2015).

Consistent with Ota et al (2014), here we demonstrate that increasing levels of REDD1 in the PFC of cacna1c HET mice is capable of reversing the antidepressant-like behavior in SPT and TST. Interestingly though REDD1 overexpression had no effect in FST, possibly due to the lower sensitivity of FST as a behavioral assay in measuring subtle changes in immobility (Castagne et al, 2011). Surprisingly however, in WT mice overexpression of REDD1 in the PFC increased sucrose preference and decreased immobility time in the TST, inconsistent with our prior observation

(Ota et al, 2014). This discrepancy may be due to a number of factors, including the SPT protocol utilized (no deprivation and $24 \mathrm{~h}$ test in this study $v s$ water deprivation with $1 \mathrm{~h}$ test), rodent species used (mouse in this study $v s$ rat) or location of viral infusions (ventral PFC in this study $v s$ dorsal PFC) that may have differential effects on depressive-like behavior because of different subcortical structures targeted by these two regions (Haber, 2011). Nevertheless, the results demonstrate that REDD1 overexpression reverses the antidepressant-like behaviors observed in cacnalc HET mice.

The mechanism of REDD1 action in the brain remains underexplored. We have reported that REDD1 mediates chronic stress-induced synaptic changes by downregulating the mTORC1 pathway involved in protein synthesisdependent synaptic changes (Ota et al, 2014). However, despite the lower REDD1 levels in the PFC of cacnalc HET mice, which would predict greater activation of mTORC1, we observed no change in mTORC1 activity. Similarly, overexpression of REDD1 in cacna 1c HET mice that reversed the antidepressant-like phenotype had no impact on the mTORC1 pathway. One possible explanation is that REDD1 may selectively regulate the mTORC1 pathway in the context of CUS-induced synaptic changes and depressive-like behavior whereas in the PFC of cacnalc HET mice, REDD1 may regulate depressive behavior by recruiting alternative pathways like the Akt and FoxO3a pathways. This is supported by the fact that several anti-depressants function in an mTOR-independent manner, such as imipramine, which may exert its antidepressant-associated changes on dendritic growth and synaptic proteins via Akt (Park et al, 2014). Similarly, chronic fluoxetine treatment induces changes in synaptic protein expression in the cortex independent of activation of mTOR (Liu et al, 2015). Thus, our findings suggest that $\mathrm{Ca}_{\mathrm{v}} 1.2$ may modulate depressive behavior via REDD1 in an mTOR-independent manner. However, the precise link between REDD1, Akt, and FoxO3a and their regulation of depressive behavior needs further investigation.

The FoxO family of transcription factors is another class of molecules that has been linked to depression-related behavior (Wang et al, 2015) with SNPs within the FoxO3a gene linked to BD (Magno et al, 2011). Rodent studies find that the antidepressant imipramine (Polter et al, 2009), as well as the mood stabilizer lithium (Mao et al, 2007), act via decreasing levels of FoxO3a in the nucleus. In line with this, FoxO3a-deficient mice exhibit antidepressant-like behavior (Polter et al, 2009; Zhou et al, 2012), suggesting that increasing levels of nuclear FoxO3a potentially via increased trafficking from the cytoplasm to the nucleus could drive depressive behavior. Consistent with these findings, REDD1 overexpression in cacna1c HET mice that reversed the antidepressant-like behavior also increased nuclear FoxO3a while decreasing cytoplasmic FoxO3a, suggesting that REDD1-induced cytoplasmic-nuclear FoxO3a trafficking is associated with REDD1-induced reversal of the antidepressant-like effect in cacnalc-deficient mice. However, the higher basal nuclear levels of FoxO3a in cacna1c HET mice that exhibit antidepressant-like behavior contradicts the above finding and suggests that higher basal levels of nuclear FoxO3a in cacnalc HET mice may not be the primary mechanism underlying the antidepressant-like phenotype in HET mice. In addition, although there was 
close to $50 \%$ higher basal levels of nuclear FoxO3a in cacna1c HET mice, this was not reflected by lower levels in the cytoplasmic fraction, further supporting that altered trafficking of FoxO3a may not be the cause of higher basal nuclear FoxO3a.

Phosphorylation of FoxO3a has been shown to limit its nuclear translocation from the cytoplasm, and thus its transcriptional effect, as shown in other systems (Brunet et al, 1999) and suggested, but not directly demonstrated, in the brain (Polter et al, 2009). Contrary to the expected lower levels of phospho-FoxO3a in the nucleus, we find higher S253 phospho-FoxO3a. Similarly, following overexpression of REDD1, both S253 and T32 phospho-FoxO3a are present at higher levels. Thus, regulation of FoxO3a by phosphorylation, at least in cacna1c HET mice, does not appear to follow the mechanisms identified in other systems. However, higher phospho-FoxO3a may still result in lower transcriptional activity as phosphorylation of FoxO3a has been shown to reduce its DNA binding to target genes (Tzivion et al, 2011). It is also plausible that in the brain FoxO3a activity is additionally regulated by other post-translational modifications such as acetylation, recently demonstrated to regulate cocaine (Ferguson et al, 2015) and social behavior (Nott et al, 2016). Thus, multiple posttranslational modifications may regulate FoxO3a activity, a question that will be addressed in future studies.

In summary, in this study, we have identified the PFC as a key brain region in which cacnalc mechanisms through previously unidentified, novel molecular pathways contribute to depression-related behavior. The above findings establish cacnalc HET mice as a useful mouse model to further our understanding of the molecular mechanisms underlying depression.

\section{FUNDING AND DISCLOSURE}

This work was supported by 1R01DA029122 (AMR), The Hartwell Foundation (AMR), Weill Cornell Autism Research Program (AMR), MH093897 (RSD), MH105910 (RSD), DA016735 (MJG), Weill Cornell Postdoctoral Fellowship (ZDK), 5F31DA032169 (ASL), and 5T32DA7274-20 (KCS). The authors declare no conflict of interest.

\section{ACKNOWLEDGMENTS}

We thank Héctor De Jesús-Cortés for help with statistical analyses and Nii Addy for helpful suggestions in manuscript preparation.

\section{REFERENCES}

Backes H, Dietsche B, Nagels A, Konrad C, Witt SH, Rietschel M et al (2014). Genetic variation in CACNA1C affects neural processing in major depression. J Psychiatr Res 53: 38-46.

Bader PL, Faizi M, Kim LH, Owen SF, Tadross MR, Alfa RW et al (2011). Mouse model of Timothy syndrome recapitulates triad of autistic traits. Proc Natl Acad Sci USA 108: 15432-15437.

Bagot RC, Labonte B, Pena CJ, Nestler EJ (2014). Epigenetic signaling in psychiatric disorders: stress and depression. Dialogues Clin Neurosci 16: 281-295.
Bhat S, Dao DT, Terrillion CE, Arad M, Smith RJ, Soldatov NM et al (2012). CACNA1C (Cav1.2) in the pathophysiology of psychiatric disease. Prog Neurobiol 99: 1-14.

Brunet A, Bonni A, Zigmond MJ, Lin MZ, Juo P, Hu LS et al (1999). Akt promotes cell survival by phosphorylating and inhibiting a Forkhead transcription factor. Cell 96: 857-868.

Can A, Dao DT, Terrillion CE, Piantadosi SC, Bhat S, Gould TD (2012). The tail suspension test. J Vis Exp 59: e3769.

Castagne V, Moser P, Roux S, Porsolt RD (2011). Rodent models of depression: forced swim and tail suspension behavioral despair tests in rats and mice. Curr Protoc Neurosci Chapter 8: Unit 8.10A.

Cohen C, Perrault G, Sanger DJ (1997). Assessment of the antidepressant-like effects of L-type voltage-dependent channel modulators. Behav Pharmacol 8: 629-638.

Covington HE 3rd, Lobo MK, Maze I, Vialou V, Hyman JM, Zaman S et al (2010). Antidepressant effect of optogenetic stimulation of the medial prefrontal cortex. J Neurosci 30: 16082-16090.

Dao DT, Mahon PB, Cai X, Kovacsics CE, Blackwell RA, Arad M et al (2010). Mood disorder susceptibility gene CACNA1C modifies mood-related behaviors in mice and interacts with sex to influence behavior in mice and diagnosis in humans. Biol Psychiatry 68: 801-810.

Ebert DH, Greenberg ME (2013). Activity-dependent neuronal signalling and autism spectrum disorder. Nature 493: 327-337.

Ferguson D, Shao N, Heller E, Feng J, Neve R, Kim HD et al (2015). SIRT1-FOXO3a regulate cocaine actions in the nucleus accumbens. J Neurosci 35: 3100-3111.

Gershon ES, Grennan K, Busnello J, Badner JA, Ovsiew F, Memon S et al (2014). A rare mutation of CACNA1C in a patient with bipolar disorder, and decreased gene expression associated with a bipolar-associated common SNP of CACNA1C in brain. Mol Psychiatry 19: 890-894.

Haber SN (2011). Neuroanatomy of reward: a view from the ventral striatum. In: Gottfried JA (ed). Neurobiology of Sensation and Reward. Chapter 11. CRC Press/Taylor \& Francis: Boca Raton (FL).

Heyes S, Pratt WS, Rees E, Dahimene S, Ferron L, Owen MJ et al (2015). Genetic disruption of voltage-gated calcium channels in psychiatric and neurological disorders. Prog Neurobiol 134: 36-54.

Hoekman MF, Jacobs FM, Smidt MP, Burbach JP (2006). Spatial and temporal expression of FoxO transcription factors in the developing and adult murine brain. Gene Expr Patterns 6: 134-140.

Huang W, Zhu PJ, Zhang S, Zhou H, Stoica L, Galiano M et al (2013). mTORC2 controls actin polymerization required for consolidation of long-term memory. Nat Neurosci 16: 441-448.

Hulmi JJ, Silvennoinen M, Lehti M, Kivela R, Kainulainen H (2012). Altered REDD1, myostatin, and Akt/mTOR/FoxO/MAPK signaling in streptozotocin-induced diabetic muscle atrophy. Am J Physiol Endocrinol Metab 302: E307-E315.

Kabir ZD, Lee AS, Rajadhyaksha AM (2016). L-type Ca channels in mood, cognition and addiction: integrating human and rodent studies with a focus on behavioural endophenotypes. J Physiol 594: 5823-5837.

Kabir ZD, Lourenco F, Byrne ME, Katzman A, Lee F, Rajadhyaksha AM et al (2012). Brain-derived neurotrophic factor genotype impacts the prenatal cocaine-induced mouse phenotype. Dev Neurosci 34: 184-197.

Kang HJ, Voleti B, Hajszan T, Rajkowska G, Stockmeier CA, Licznerski $P$ et al (2012). Decreased expression of synapse-related genes and loss of synapses in major depressive disorder. Nat Med 18: 1413-1417.

Kessler RC, Berglund P, Demler O, Jin R, Merikangas KR, Walters EE (2005). Lifetime prevalence and age-of-onset distributions of DSM-IV disorders in the National Comorbidity Survey Replication. Arch Gen Psychiatry 62: 593-602.

Knackstedt LA, Moussawi K, Lalumiere R, Schwendt M, Klugmann M, Kalivas PW (2010). Extinction training after 
cocaine self-administration induces glutamatergic plasticity to inhibit cocaine seeking. J Neurosci 30: 7984-7992.

Koester SE, Insel TR (2016). Understanding how non-coding genomic polymorphisms affect gene expression. Mol Psychiatry 21: 448-449.

Krey JF, Paşca SP, Shcheglovitov A, Yazawa M, Schwemberger R, Rasmusson $\mathrm{R}$ et al (2013). Timothy syndrome is associated with activity-dependent dendritic retraction in rodent and human neurons. Nat Neurosci 16: 201-209.

Lee AS, Ra S, Rajadhyaksha AM, Britt JK, De Jesus-Cortes H, Gonzales KL et al (2012). Forebrain elimination of cacnalc mediates anxiety-like behavior in mice. Mol Psychiatry 17: 1054-1055.

Lee DK, Kim JH, Kim WS, Jeoung D, Lee H, Ha KS et al (2015). Lipopolysaccharide induction of REDD1 is mediated by two distinct CREB-dependent mechanisms in macrophages. FEBS Lett 589(19 Pt B): 2859-2865.

Liu XL, Luo L, Mu RH, Liu BB, Geng D, Liu Q et al (2015). Fluoxetine regulates $\mathrm{mTOR}$ signalling in a region-dependent manner in depression-like mice. Sci Rep 5: 16024.

Magno LA, Santana CV, Sacramento EK, Rezende VB, Cardoso MV, Maurício-da-Silva L et al (2011). Genetic variations in FOXO3A are associated with Bipolar Disorder without confering vulnerability for suicidal behavior. J Affect Disord 133: 633-637.

Maiese K, Chong ZZ, Shang YC, Wang S (2013). mTOR: on target for novel therapeutic strategies in the nervous system. Trends $\mathrm{Mol}$ Med 19: 51-60.

Mao Z, Liu L, Zhang R, Li X (2007). Lithium reduces FoxO3a transcriptional activity by decreasing its intracellular content. Biol Psychiatry 62: 1423-1430.

Martinowich K, Manji H, Lu B (2007). New insights into BDNF function in depression and anxiety. Nat Neurosci 10: 1089-1093.

Mogilnicka E, Czyrak A, Maj J (1987). Dihydropyridine calcium channel antagonists reduce immobility in the mouse behavioral despair test; antidepressants facilitate nifedipine action. Eur $J$ Pharmacol 138: 413-416.

Mogilnicka E, Czyrak A, Maj J (1988). BAY K 8644 enhances immobility in the mouse behavioral despair test, an effect blocked by nifedipine. Eur J Pharmacol 151: 307-311.

Moosmang S, Haider N, Klugbauer N, Adelsberger H, Langwieser N, Müller J et al (2005). Role of hippocampal Cav1.2 Ca2+ channels in NMDA receptor-independent synaptic plasticity and spatial memory. J Neurosci 25: 9883-9892.

Nott A, Cheng J, Gao F, Lin YT, Gjoneska E, Ko T et al (2016). Histone deacetylase 3 associates with $\mathrm{MeCP} 2$ to regulate FOXO and social behavior. Nat Neurosci 19: 1497-1505.

Ota KT, Liu RJ, Voleti B, Maldonado-Aviles JG, Duric V, Iwata M et al (2014). REDD1 is essential for stress-induced synaptic loss and depressive behavior. Nat Med 20: 531-535.

Park SW, Lee JG, Seo MK, Lee CH, Cho HY, Lee BJ et al (2014). Differential effects of antidepressant drugs on mTOR signalling in rat hippocampal neurons. Int $J$ Neuropsychopharmacol 17: 1831-1846.

Polter A, Yang S, Zmijewska AA, van Groen T, Paik JH, Depinho RA et al (2009). Forkhead box, class $O$ transcription factors in brain: regulation and behavioral manifestation. Biol Psychiatry 65: 150-159.

Porsolt RD, Brossard G, Hautbois C, Roux S (2001). Rodent models of depression: forced swimming and tail suspension behavioral despair tests in rats and mice. Curr Protoc Neurosci Chapter 8: Unit 8.10A.
Pothion S, Bizot JC, Trovero F, Belzung C (2004). Strain differences in sucrose preference and in the consequences of unpredictable chronic mild stress. Behav Brain Res 155: 135-146.

Rajadhyaksha A, Barczak A, Macias W, Leveque JC, Lewis SE, Konradi C (1999). L-Type $\mathrm{Ca}(2+)$ channels are essential for glutamate-mediated CREB phosphorylation and c-fos gene expression in striatal neurons. J Neurosci 19: 6348-6359.

Rajkowska G, Miguel-Hidalgo JJ, Wei J, Dilley G, Pittman SD, Meltzer HY et al (1999). Morphometric evidence for neuronal and glial prefrontal cell pathology in major depression. Biol Psychiatry 45: 1085-1098.

Roussos P, Mitchell AC, Voloudakis G, Fullard JF, Pothula VM, Tsang $J$ et al (2014). A role for noncoding variation in schizophrenia. Cell Rep 9: 1417-1429.

Schierberl K, Hao J, Tropea TF, Ra S, Giordano TP, Xu Q et al (2011). Cav1.2 L-type $\mathrm{Ca}^{2+}$ channels mediate cocaine-induced GluA1 trafficking in the nucleus accumbens, a long-term adaptation dependent on ventral tegmental area $\mathrm{Ca}(\mathrm{v}) 1.3$ channels. J Neurosci 31: 13562-13575.

Seisenberger C, Specht V, Welling A, Platzer J, Pfeifer A, Kühbandner $S$ et al (2000). Functional embryonic cardiomyocytes after disruption of the L-type alpha1C (Cav1.2) calcium channel gene in the mouse. J Biol Chem 275: 39193-39199.

Splawski I, Timothy KW, Decher N, Kumar P, Sachse FB, Beggs AH et al (2005). Severe arrhythmia disorder caused by cardiac L-type calcium channel mutations. Proc Natl Acad Sci USA 102: 8089-8096, discussion 8086-8088.

Tao X, Finkbeiner S, Arnold DB, Shaywitz AJ, Greenberg ME (1998). $\mathrm{Ca} 2+$ influx regulates BDNF transcription by a CREB family transcription factor-dependent mechanism. Neuron 20: 709-726.

Tropea TF, Kabir ZD, Kaur G, Rajadhyaksha AM, Kosofsky BE (2011). Enhanced dopamine D1 and BDNF signaling in the adult dorsal striatum but not nucleus accumbens of prenatal cocaine treated mice. Front Psychiatry 2: 67.

Tzivion G, Dobson M, Ramakrishnan G (2011). FoxO transcription factors; Regulation by AKT and 14-3-3 proteins. Biochim Biophys Acta 1813: 1938-1945.

Vialou V, Feng J, Robison AJ, Nestler EJ (2013). Epigenetic mechanisms of depression and antidepressant action. Annu Rev Pharmacol Toxicol 53: 59-87.

Wang H, Quirion R, Little PJ, Cheng Y, Feng ZP, Sun HS et al (2015). Forkhead box $\mathrm{O}$ transcription factors as possible mediators in the development of major depression. Neuropharmacology 99: 527-537.

Wang Y, Zhou Y, Graves DT (2014). FOXO transcription factors: their clinical significance and regulation. Biomed Res Int 2014: 925350.

Yoshimizu T, Pan JQ, Mungenast AE, Madison JM, Su S, Ketterman J et al (2015). Functional implications of a psychiatric risk variant within CACNA1C in induced human neurons. Mol Psychiatry 20: 162-169.

Zhang H, Fu Y, Altier C, Platzer J, Surmeier DJ, Bezprozvanny I (2006). Ca1.2 and CaV1.3 neuronal L-type calcium channels: differential targeting and signaling to pCREB. Eur J Neurosci 23: 2297-2310.

Zhou W, Chen L, Yang S, Li F, Li X (2012). Behavioral stressinduced activation of FoxO3a in the cerebral cortex of mice. Biol Psychiatry 71: 583-592.

Zhu W, Bijur GN, Styles NA, Li X (2004). Regulation of FOXO3a by brain-derived neurotrophic factor in differentiated human $\mathrm{SH}-$ SY5Y neuroblastoma cells. Brain Res Mol Brain Res 126: 45-56.

Supplementary Information accompanies the paper on the Neuropsychopharmacology website (http://www.nature.com/npp) 